\title{
Genomic characterization of Listeria monocytogenes isolates reveals that their persistence in a pig slaughterhouse is linked to the presence of benzalkonium chloride resistance genes
}

\author{
Tamazight Cherifi ${ }^{1,2,3^{*}}$ (D), Catherine Carrillo ${ }^{4}$, Dominic Lambert ${ }^{4}$, Ilhem Miniai ${ }^{1,2,3}$, Sylvain Quessy ${ }^{1,2,3}$, \\ Guillaume Larivière-Gauthier ${ }^{1,2,3}$, Burton Blais ${ }^{4^{*}}$ and Philippe Fravalo $0^{1,2,3^{*}}$
}

\begin{abstract}
Background: The aim of this study was to characterize the genomes of 30 Listeria monocytogenes isolates collected at a pig slaughterhouse to determine the molecular basis for their persistence.

Results: Comparison of the $30 \mathrm{~L}$. monocytogenes genomes showed that successive isolates (i.e., persistent types) recovered from thew sampling site could be linked on the basis of single nucleotide variants confined to prophage regions. In addition, our study revealed the presence among these strains of the $b c r A B C$ cassette which is known to produce efflux pump-mediated benzalkonium chloride resistance, and which may account for the persistence of these isolates in the slaughterhouse environment. The presence of the bcrABC cassette was confirmed by WGS and $P C R$ and the resistance phenotype was determined by measuring minimum inhibitory concentrations. Furthermore, the BC-resistant strains were found to produce lower amounts of biofilm in the presence of sublethal concentrations of $\mathrm{BC}$.

Conclusions: High resolution SNP-based typing and determination of the $b c r A B C$ cassette may provide a means of distinguishing between resident and sporadic L. monocytogenes isolates, and this in turn will support better management of this pathogen in the food industry.
\end{abstract}

Keywords: bcrABC cassette, Benzalkonium chloride resistance genes, Listeria monocytogenes, Pig slaughterhouse, Whole genome sequences

\section{Background}

Listeria monocytogenes is a bacterial pathogen that causes listeriosis, the foodborne illness with the highest fatality rate $[1,2]$. The ability of this organism to colonize and persist in food processing plants increases the risk of food contamination [3]. Persistent strains have been involved in some listeriosis outbreaks [4-6],

\footnotetext{
* Correspondence: ctamazight@gmail.com; Burton.Blais@inspection.gc.ca; philippe.fravalo@umontreal.ca

${ }^{1}$ Chaire de Recherche en Salubrité des Viandes, Faculté de Médecine Vétérinaire, Université de Montréal, Saint-Hyacinthe, QC, Canada

${ }^{4}$ Food Microbiology Research Team, Canadian Food Inspection Agency, Ottawa, ON, Canada

Full list of author information is available at the end of the article
}

making persistent contamination of L. monocytogenes an important consideration for public health. The importance of the persistence of $L$. monocytogenes in food processing plants has been previously discussed [7-9]. Whereas some L. monocytogenes strains can persist within the food processing environment for years [3], some strains are merely transitory in these environments, and the approaches for their mitigation will be very different (i.e., different sanitation regimens). Many genetically distinct $L$. monocytogenes strains can be isolated sporadically during different sampling periods while other persistent strains can be isolated over the same periods [10-12]. Although several explanations

(c) The Author(s). 2018 Open Access This article is distributed under the terms of the Creative Commons Attribution 4.0 International License (http://creativecommons.org/licenses/by/4.0/), which permits unrestricted use, distribution, and 
have been proposed for the persistence of specific $L$. monocytogenes strains [13], the reasons are not fully understood. It has been postulated that $L$. monocytogenes strains persist due to opportunistic colonization of harborage sites in food processing facility premises and on equipment [13]. Alternatively, it has been suggested that the persistence of $L$. monocytogenes is linked to its ability to produce biofilms [14, 15]. Other studies using phenotypic methods have observed resistance to quaternary ammonium compounds (QAC) in persistent strains [16-19]. Recently, genetic factors associated with the QAC-resistance phenotype and resistance to benzalkonium chloride (BC), a QAC largely used in the food industry, were identified [17, 2023]. These include the benzalkonium chloride resistance cassette $b c r A B C$ [21], in which $b c r A B$ code for the small multidrug resistance protein family (SMR) transporters and bcrC codes for a transcriptional factor [23]. In addition, the qacH gene which codes for a SMR transporter associated with the export of benzalkonium chloride and acquired by the Tn6188 transposon [19, 20, 24], and other QAC determinants originally observed in Staphylococci [25].

Although there is no consensus on the definition of a persistent strain, a persistent status should be considered when the same molecular type is isolated many times at different visits within the same processing plant for a defined period of time [13]. Therefore, identification of recurring highly genetically related isolates is the first step necessary in studying the association between resistance to $\mathrm{BC}$ and persistence. The persistence designation used in previous studies was based on pulsed-field gel electrophoresis (PFGE) typing [19, 24], an international standardized method for L. monocytogenes characterization. However, recent studies using whole-genome sequencing (WGS) enabling the core genome/whole genome MLST (cgMLST/wgMLST) analyses and single nucleotide variant (SNV) analyses have demonstrated that a better discriminatory power can be achieved [26, 27]. WGS-based typing methods may allow for better clustering of highly-related persistent isolates.

In this study, we set to characterize three groups of $L$. monocytogenes strains - two persistent and one sporadic - isolated from a pig slaughterhouse, with a particular emphasis on the $\mathrm{BC}$ resistance genotype/phenotype of these strains. We also performed complementary analyses to identify high quality single nucleotide variants (hqSNVs) and predict affected functions on the basis of these SNVs.

\section{Materials and methods}

\section{Sampling, bacterial isolation, and pulsed field gel} electrophoresis characterization

Sampling procedures, bacterial isolation and pulsed-field gel electrophoresis (PFGE) typing were performed according to Lariviere-Gauthier et al., [12]. Briefly, bacterial strains were isolated from repeated environmental sampling at a pork slaughterhouse and cutting facility. The samples used in this study were collected during three separate visits over a one-month period, with an interval of 2 weeks between visits 1 and 2 and 1 week between visits 2 and 3. Samples were collected using pre-moistened swabs, after cleaning and sanitation procedures, on environmental surfaces in contact or not with the products, a list of surface types is detailed in Table 1. The disinfectant concentration used in this slaughterhouse, and specifically in cutting facility, was from 150 to $200 \mathrm{ppm}$.

Another strain, Lis 8316 belonging to the group B was isolated 3 years after in the same slaughterhouse.

Detection of Listeria monocytogenes was performed using Health Canada's MFHPB-30 based-method as described previously [12], briefly, two enrichment broths were used. The first enrichment was conducted in University of Vermont medium 1 broth (UVM-1; Lab M, Heywood, United Kingdom) for $24 \mathrm{~h}$ at $30 \mathrm{C}^{\circ}$, and the second in Fraser broth (Lab $\mathrm{M}$, United Kingdom) for $48 \mathrm{~h}$ at $37 \mathrm{C}^{\circ}$. Selective Listeria Ottavani and Agosti (ALOA; AES Chemunex, Bruz, France) agar was used to isolate $L$. monocytogenes strains from the two broths and the identification of isolates were based on the use of carbohydrates, Christie-Atkins-Munch-Petersen (CAMP test), hemolysis and motility.

The pulsed field gel electrophoresis characterization of isolates was based on the Center disease and control center (CDC) PulseNet protocol [28]. Pattern analysis was performed using Bionumerics software (version 6.5, Applied Maths, Kortrijk, Belgium) and strains were clustered with the unweighted pair group method with arithmetic means.

For whole genome sequencing, strains were selected according to their recurrence during the sampling period (transient vs persistent). PFGE type 1 and 16 belonging to the sequence type (ST) 5 and 9 respectively, were considered persistent since they were isolated at each visit and after cleaning and sanitation procedures (respectively named persistent B and A). PFGE types 6,10 , 9, 18, 8 respectively with a ST of $6,5,5,9$ and 1 were considered to be transient or sporadic strains since they were isolated only at one visit. The persistent group A and $\mathrm{B}$ and sporadic strains are phylogenetically unrelated, even if the sporadic strain p961 (pulsotype 18) showed a polymorphism of three different bands with the group A considering Apa1 and AscI restriction profiles. A PFGE profiles of a representative strains from the group A and B and p961 strain (pulsotype 18) were given in a Additional file 1: Figure S1. The numbers and characteristic selection of isolates are detailed in Table 1.

\section{DNA extraction and sequencing}

One $\mathrm{mL}$ of Brain Heart Infusion (BHI) broth (Becton and Dickinson, Franklin Lakes, NJ, USA) was inoculated 
Table 1 Strain origin and pulsotype (as determined by CDC PulseNet PFGE protocol) of isolates obtained during monitoring sampling of an industrial slaughterhouse over a four weeks period

\begin{tabular}{|c|c|c|c|c|}
\hline Isolates & $\begin{array}{l}\text { ST ID } \\
\left.\text { (PFGE type }{ }^{a}\right)\end{array}$ & Isolate characteristics ${ }^{\mathrm{b}}$ & Isolation dates (visit) & Origin \\
\hline p960 & & & $2011-02-26(1)$ & Viscera tank \\
\hline p962 & & & $2011-02-26(1)$ & Chilling door \\
\hline p958 & & Persistent Group A & $2011-02-26(1)$ & Saw \\
\hline p975 & ST9 (16) & & 2011-03-19 (2) & Saw \\
\hline p985 & & & 2011-03-27 (3) & Saw \\
\hline p984 & & & 2011-03-27 (3) & Bleeding \\
\hline \multicolumn{5}{|l|}{ p963 } \\
\hline \multicolumn{5}{|l|}{ p974 } \\
\hline p964 & ST5 (1) & & $2011-02-26(1)$ & \\
\hline \multicolumn{5}{|l|}{ p966 } \\
\hline \multicolumn{5}{|l|}{ p967 } \\
\hline \multicolumn{5}{|l|}{ p965 } \\
\hline \multicolumn{5}{|l|}{ p968 } \\
\hline p971 & & & & meat conveyor \\
\hline p972 & ST5 (1) & Persistent Group B & 2011-03-19 (2) & \\
\hline \multicolumn{5}{|l|}{ p969 } \\
\hline \multicolumn{5}{|l|}{ p970 } \\
\hline \multicolumn{5}{|l|}{ p973 } \\
\hline \multicolumn{5}{|l|}{ p980 } \\
\hline \multicolumn{5}{|l|}{ p977 } \\
\hline p978 & ST5 (1) & & 2011-03-27 (3) & \\
\hline \multicolumn{5}{|l|}{ p979 } \\
\hline \multicolumn{5}{|l|}{ p981 } \\
\hline \multicolumn{5}{|l|}{ p982 } \\
\hline lis8316 & ST5 (1) & & 2014-01-12 & \\
\hline p959 & ST5(10) & & $2011-02-26(1)$ & Line \\
\hline p961 & ST9(18) & & $2011-02-26(1)$ & Chilling entry \\
\hline p957 & $\mathrm{ST} 1(8)$ & Sporadic Group C & $2011-02-26(1)$ & Saw \\
\hline p976 & ST5(9) & & 2011-03-19 (2) & Floor \\
\hline p983 & ST6(6) & & 2011-03-27 (3) & Door \\
\hline
\end{tabular}

aPFGE type corresponds to the Chaire de recherche en salubrité des viandes (CRSV) nomenclature [12]

${ }^{b}$ Persistent vs sporadic groups determined by PFGE

with a single colony of $L$. monocytogenes and incubated for 4 to $6 \mathrm{~h}$ at $37^{\circ} \mathrm{C}$. Bacterial cells were collected from $400 \mu \mathrm{L}$ of culture by centrifuging at 15,000 x g for $2 \mathrm{~min}$. Bacterial pellets were resuspended in $200 \mu \mathrm{L}$ of lysis buffer containing 1\% Triton X-100 (Sigma-Aldrich, ON, Canada) and $10 \mathrm{mg} / \mathrm{mL}$ lysozyme (Fisher scientific, ON, Canada) and incubated for $20 \mathrm{~min}$ at $37^{\circ} \mathrm{C}$. Genomic DNA (gDNA) was extracted using the Maxwell ${ }^{\circ} 16$ Cell LEV DNA Purification kit (Promega, Madison, WI) as recommended by the manufacturer. DNA was then quantified using the Quant-i $\mathrm{T}^{\mathrm{ma}}$ High-Sensitivity DNA Assay Kit (Life Technologies Inc., Burlington, ON).
Sequencing libraries were constructed from $1 \mathrm{ng}$ of gDNA using Nextera XT DNA Sample Preparation and Index Kits (Illumina, Inc., San Diego, CA) according to manufacturers' instructions. Genomic sequencing was performed on the Illumina MiSeq Platform (Illumina, Inc.) using a 600-cycle MiSeq Reagent kit v3 (Illumina, Inc.).

\section{Genome and plasmid assembly and annotation}

Reads were quality checked and de novo assembled using SPAdes 3.12.0 [29] with default settings. The resulting draft genomes were analyzed for assembly 
quality using Quast 4.1 [30]. For plasmid assembly, plasmidSPAdes [29] pipeline was used to assemble only the plasmid from the WGS data using the default settings. To identify the presence of large plasmid pLM80 harboring the bcrABC cassette, the resulting plasmid assemblies were blasted online using the basic local alignment search tool (Blastn) from the National Center for Biotechnology Information's (NCBI) website (https://blast.ncbi.nlm.nih.gov/Blast.cgi) with default settings using the nucleotide collection $(\mathrm{nr} / \mathrm{nt})$ database.

\section{Core genome MLST (cgMLST) characterization}

cgMLST was conducted using a genome based characterization method developed by Moura et al. [26]. The assembled 30 genomes were submitted to the Institut Pasteur's website (http://bigsdb.pasteur.fr/listeria/listeria.html) for cgMLST typing using 1748 loci and a cgMLST type (CT) was defined as a group of cgMLST profiles that differ by up to seven allelic mismatches out of 1748 loci.

\section{High quality core genome single nucleotide variant (hqSNV) analysis}

The paired end reads of closely related isolates were quality trimmed and analyzed for hqSNV detection by using the SNVPhyl core genome hqSNV pipeline (https:// github.com/apetkau/core-phylogenomics) [31], available as a tool shed in Galaxy (https://toolshed.g2.bx.psu.edu/). Briefly, the reference genomes were analyzed with PHASTER $[32,33]$ for identifying phage regions. The paired end reads were mapped against the reference genomes using SMALT v0.7.5 (http://www.sanger.ac.uk/science/ tools/smalt-0). The FreeBayes 0.9.20 was used to call the high-quality variants with a minimum depth coverage of 15 and a minimum mapping quality of 30 . The minimum SNV abundance ratio was adjusted at 0.75 . The uncalled positions were analyzed for sufficient coverage with the BCFtools that came in the SAMtools package. Reference genomes EGD-e (NCBI reference number NC003210.1) and $1 / 2 b$ str $10-0810$ (NCBI reference number NZ_CP007168.1) were used for groups A and B respectively, according to their phylogenetically relatedness throughout all analyses.

\section{SNV analysis}

The resulting variants (hqSNVs) were annotated and filtered to the reference genome Listeria monocytogenes EGD-e (NC003210.1) with snpEff and snpSift program respectively [34] for the prediction of affected functions based on the identification of genes in which the mutations were found. In this study, only the high impact hqSNVs were taken into consideration (i.e. SNVs leading to a stop gained, start loss, or a frameshift).
Screening of benzalkonium chloride resistance genes in $L$. monocytogenes strains

Identification of genetic determinants for resistance was conducted at the Institut Pasteur, according to their established protocol [26]. Briefly, a set of resistance genes was identified based on previous studies [35-37] and PATRIC, a public resistance gene database [38]. A BLASTn algorithm was used to identify the resistant genes with a minimum nucleotide identity of $70 \%$ and alignment length coverage of $70 \%$. The results were represented in a presence-absence heatmap using the phandango visualization tool [39].

\section{Minimal inhibitory concentration of $B C$ and PCR screening for $b c r A B C$}

To determine if the persistent groups were resistant to $\mathrm{BC}$, Minimal inhibitory concentrations (MICs) were determined according to the clinical and laboratory standards institute (CLSI) guidelines with minor modifications. Briefly, tryptic soy broth with yeast extract (TSBYE) supplied with BC (Sigma-Aldrich, ON, Canada) at a final concentration covering a range from 0 to $200 \mathrm{ppm}$ was inoculated with $10^{-5} \mathrm{CFU}$ from an overnight culture. The plates were incubated at $30^{\circ} \mathrm{C}$ for $48 \mathrm{~h}$. The MIC was defined as the lowest concentration at which a growth inhibition was observed. The assay was conducted in triplicate.

PCR was used to confirm the presence of $b c r A B C$ genes. DNA was extracted from sporadic and persistent strains using Chelex (Biorad, Mississauga, ON, CA) as follows: isolates were plated on blood sheep agar and colonies were picked and resuspended in $50 \mu \mathrm{L}$ of Chelex at $0.6 \%(w / v)$. The suspensions were heated first at $55^{\circ} \mathrm{C}$ for $30 \mathrm{~min}$ and then at $98^{\circ} \mathrm{C}$ for $15 \mathrm{~min}$ and were vortexed between steps. The solutions were centrifuged at $12000 \mathrm{rpm}$ and the upper phase containing DNA was transferred to a clean tube and stored at $4{ }^{\circ} \mathrm{C}$ for quick use. The PCR parameters consisted of an initial denaturation of $98^{\circ} \mathrm{C}$ for $30 \mathrm{~s}$ followed by 30 cycles of denaturation at $98^{\circ} \mathrm{C}$ for $30 \mathrm{~s}$, annealing at $60^{\circ} \mathrm{C}$ for $40 \mathrm{~s}$, elongation at $72{ }^{\circ} \mathrm{C}$ for $1.30 \mathrm{~min}$, and final elongation at $72^{\circ} \mathrm{C}$ for $5 \mathrm{~min}$. The primers used here were designed in a previous study $[21,40]$.

\section{Biofilm formation ability}

Isolates from all groups were tested for biofilm formation ability using the microtiter plate assay in the presence and absence of BC (Sigma-Aldrich, ON, Canada), briefly, an overnight culture in tryptic soy broth supplemented with $0.6 \%(w / v)$ of yeast extract was inoculated to BHI (Becton and Dickinsen, Franklin Lakes, NJ, USA) supplemented or not with 3.125 and $0,78 \mathrm{ppm}$ of BC (at final concentration) at $1 / 1000.100 \mu \mathrm{L}$ of the inoculated BHI was distributed into each well of 96 well microplates (Costar ${ }^{\circ}$ 3370; Corning, NY, USA) and incubated 
at $30{ }^{\circ} \mathrm{C}$ for $48 \mathrm{~h}$. The supernatant was discarded from the mature biofilm and this latter washed to eliminate planktonic cells before stained with Cristal Violet (CV) $0.1 \%(\mathrm{w} / \mathrm{v})$ for $20 \mathrm{~min}$ and washed two times. Ethanol 95\% was used to solubilize CV within biofilm and Optical density (Od) was taken at $595 \mathrm{~nm}$. Experiment was repeated in triplicate at different days.

\section{Statistical analysis}

To determine if there were differences in biofilm formation capacity between strains from the three groups in the presence and absence of $\mathrm{BC}$, linear mixed model was performed on the data of groups $(\mathrm{A}, \mathrm{B}, \mathrm{C})$ and treatments (control, 3.125 and $0.78 \mathrm{ppm}$ ) as fixed factors and isolate as random factor. A series of a priori contrasts were conducted to compare the mean in the control groups with the mean in the other two treatments in each group and to compare the mean in each group for each treatment. Alpha level was adjusted with Benjamini-Hochberg procedure. Results were significantly different if $p<0.05$.

\section{Results}

A total of $30 \mathrm{~L}$. monocytogenes strains was isolated: 25 were persistent, present during all visits, and 5 were sporadic, present during a single visit. The 25 persistent isolates were sub-divided into 2 Groups, A, 6 isolates, and $\mathrm{B}, 19$ isolates, based on their pulsotypes. The 5 sporadic isolates were assigned to Group C (Table 1).

The cgMLST analysis showed eight cgMLST types (CT) corresponding to the six Pulsotypes. It is noteworthy that all of the CTs observed in our study were new in the BIGSdb database of the Institut Pasteur (at time of analysis). All of the strains from the group B (pulsotype 1) belonged to the new CT2802 whereas the strains from group A (pulsotype 16) showed two different CTs, with one strain belonging to CT4145 and the rest of the group to CT2825 (Fig. 1). Interestingly, the sporadic strain p961 (pulsotype 18) from sporadic strains group was closely related to persistent group $\mathrm{A}$, and sporadic strains p959 and p976 were closely related to group B (Fig. 1).

The SNVphyl analysis showed some differences in hqSNV's numbers within the persistent strains: with 0 to 25 hqSNVs in group A and 0 to 13 hqSNVs in group B. Thus, in group A, only the p984 strain exhibited a high number of hqSNVSs (25) and was more distant from the remaining strains (Fig. 2a). Almost all the strains from group B harbored $4 \mathrm{hqSNV}$ differences or fewer, except P978, p965 and Lis8316 strains which had more hqSNV differences compared to the rest of group B. This was reflected by the close positions in the phylogenetic tree (Fig. 2b).

\section{SNVs confined mostly to prophage regions}

To study different functions affected by mutations, hqSNVs were analyzed with the snpEff program. The inferred function of impacted proteins by the hqSNVs were mostly related to bacteriophage proteins, particularly in group A (Fig. 3). Most of the hqSNVs were found within phage A118 (Table 2A). Furthermore, the position of these phages within the genome was the same between the unrelated persistent groups $A$ and $B$ (Table $2 \mathrm{~A}$ and $\mathrm{B}$ ). There were $8 \mathrm{hqSNVs}$ that were detected in genes coding for known functions of the $L$. monocytogenes core genome in group $\mathrm{B}$, but five out of these eight were present in only one to four strains

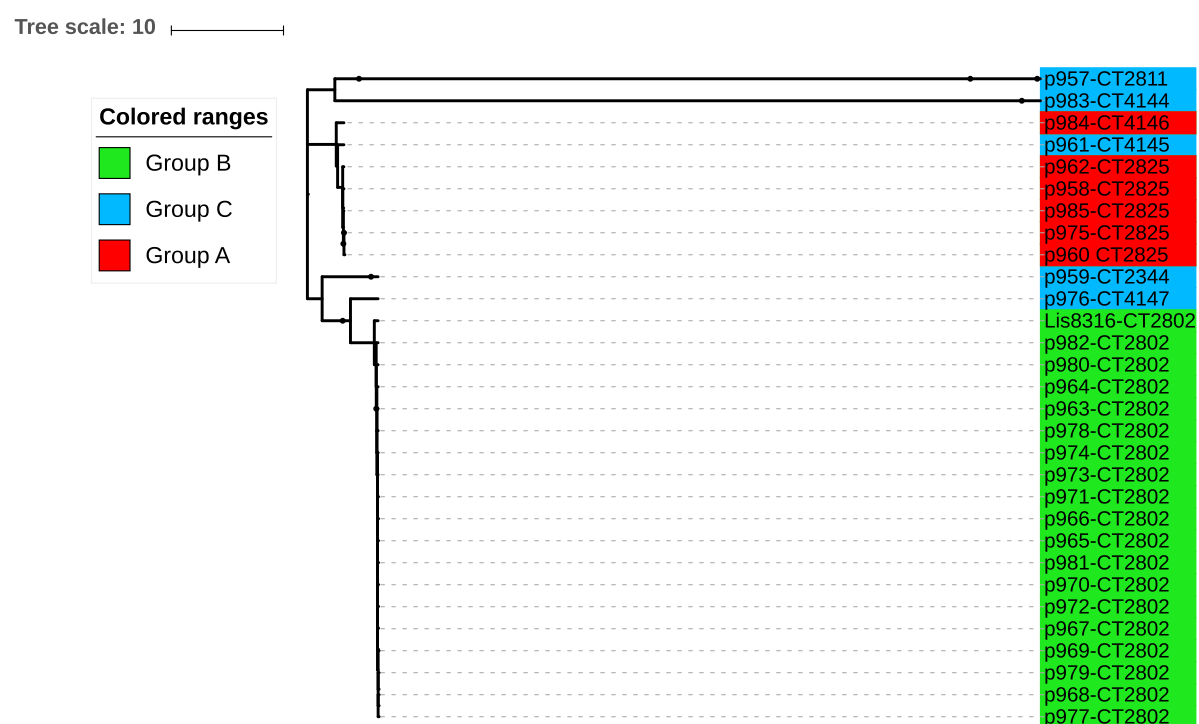

Fig. 1 Phylogeny reconstruction of the persistent groups A, B and the sporadic strains group C isolated from an industrial slaughterhouse over a 4 weeks period; the tree was based on the cgMLST allelic profile distances. The interactive tree of life (ITOL) was used to visualize the tree [57] 
A

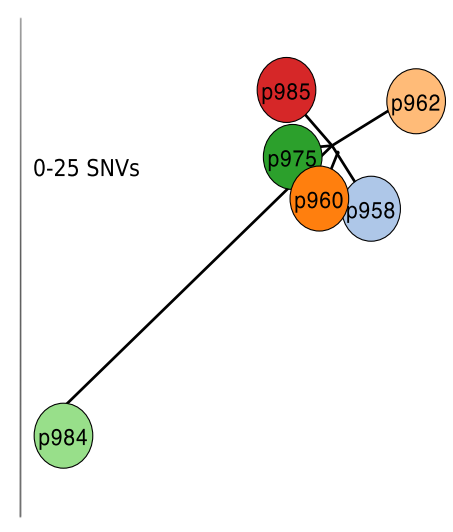

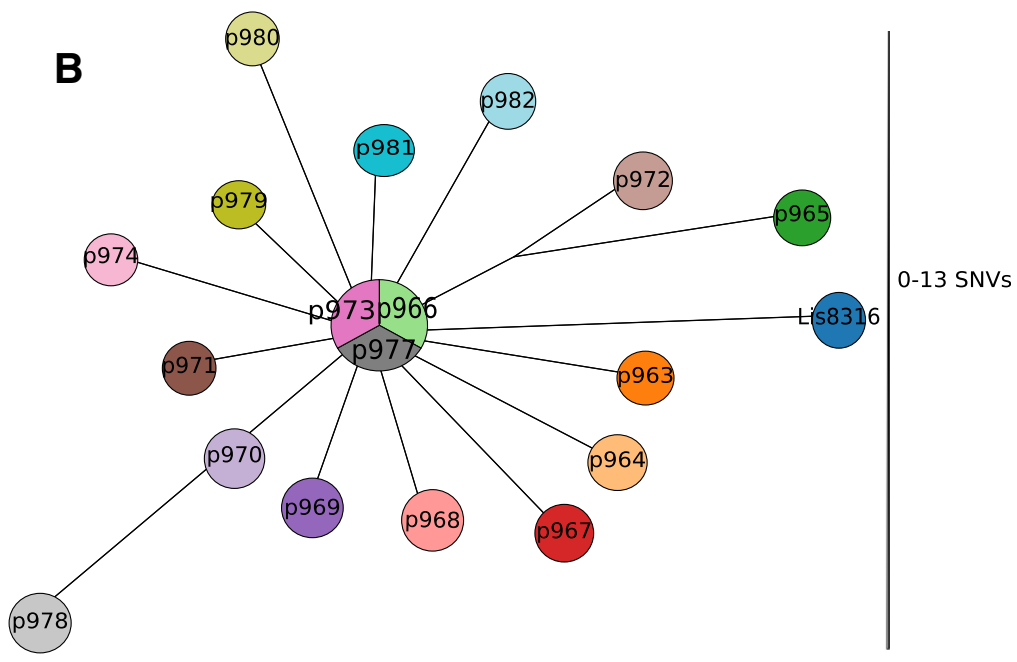

Fig. 2 Minimum spanning tree based on high quality core genome SNV positions identified amongst 6 genomes over $80 \%$ of the reference genome for the group A (a), and amongst 19 genomes over $80 \%$ of the reference genome for the group B (b). The visualization of the MST was done using GrapeTree [58]

(Table 2B). Otherwise, in group B, a SNV in the comk gene was identified at a position that resulted in a disruption of this gene due to loss of a stop codon (Table 2B). A stop codon in the inlA gene was detected as well as the SNVs, and this was confirmed by Sanger sequencing of the internalin A gene (inlA) in group B strains in a previous study [12]. These SNVs lead to a premature stop codon (PMSC). Interestingly, another SNV was detected in an internalin $B$ gene (inlB) confirmed by BLASTn. The rest of the SNVs were detected in genes coding for hypothetical proteins. Among them, many shared similarities with the A118 phage proteins (Additional file 2: Table S1).

\section{Presence of $b c r A B C$ in a persistent strains group $B$}

In order to study the presence or absence of genes associated with the persistence phenotype, identification of accessory genes was conducted on the persistent groups as well as on the five different sporadic strains isolated from the same slaughterhouse. Our results showed the

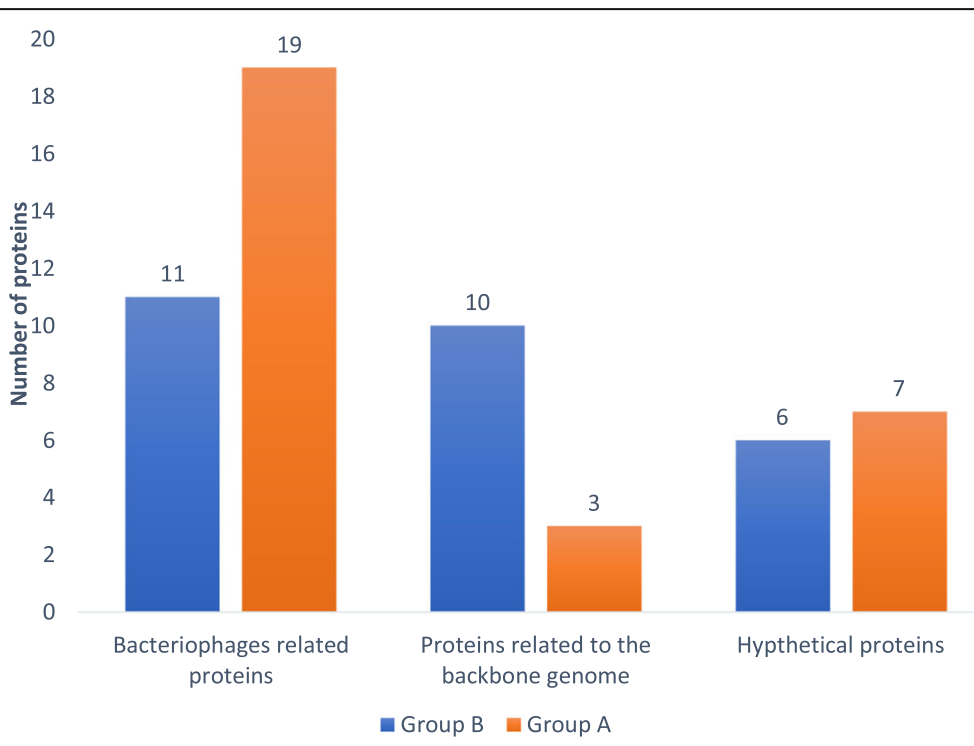

Fig. 3 Number of SNVs in Listeria monocytogenes strains isolated from an industrial slaughterhouse over fourweeks according to their annotations and function predictions using the snpEff in the persistent groups A and B. All the inferred functions to the known bacteriophage proteins were grouped in "Bacteriophage proteins", all hypothetical proteins were grouped in one cluster, and the other affected functions related to the backbone genome of L. monocytogenes were grouped 
Table 2 Composition of the annotated high impact SNVs in the persistent groups A (Table A) and B (Table B) in Listeria monocytogenes strains isolated from an industrial slaughterhouse over four weeks with their position and the altered nucleotide according to the references of the respective persistent groups

\begin{tabular}{|c|c|c|c|}
\hline$\overline{S N V S}$ & REF-ALT ${ }^{a}$ & Position & Protein inference \\
\hline \multicolumn{4}{|l|}{ A) } \\
\hline $\mathrm{H} 28$ & A-T & $2,365,617$ & holin \\
\hline $\mathrm{H} 2$ & C-A & $2,366,926$ & protein gp20 \\
\hline $\mathrm{H} 6$ & $A-C$ & $2,370,180$ & Protein gp17 \\
\hline $\mathrm{H} 11$ & G-T & $2,371,838$ & putative tape-measure \\
\hline $\mathrm{H} 12$ & G-T & $2,376,360$ & Protein gp15 \\
\hline $\mathrm{H} 13$ & $A-T$ & $2,378,030$ & Portein gp11 \\
\hline $\mathrm{H} 7$ & $\mathrm{G}-\mathrm{C}$ & $2,383,240$ & putative portal protein \\
\hline $\mathrm{H} 8$ & $\mathrm{G}-\mathrm{C}$ & $2,387,299$ & Protein gp66 \\
\hline $\mathrm{H} 23$ & $\mathrm{~T}-\mathrm{C}$ & $2,396,331$ & Protein gp43 \\
\hline $\mathrm{H} 14$ & C-A & $1,134,999$ & Cadmium resistance protein \\
\hline $\mathrm{H} 20$ & T-A & $2,268,215$ & $\begin{array}{l}\text { putative peptidoglycan bound protein } \\
\text { (LPXTG motif) }\end{array}$ \\
\hline $\mathrm{H} 3$ & G-A & $2,397,250$ & Hypothetical protein \\
\hline $\mathrm{H} 21$ & G-A & $2,398,304$ & Hypothetical protein \\
\hline $\mathrm{H} 4$ & C-A & $2,399,019$ & Hypothetical protein \\
\hline $\mathrm{H} 22$ & T-A & $2,435,024$ & Hypothetical protein \\
\hline $\mathrm{H} 24$ & $\mathrm{~T}-\mathrm{C}$ & $2,725,852$ & Hypothetical protein \\
\hline $\mathrm{H} 29$ & C-T & $2,806,268$ & Hypothetical protein \\
\hline $\mathrm{H} 30$ & C-T & $2,862,889$ & Hypothetical protein \\
\hline $\mathrm{H} 25$ & $A-G$ & $2,928,670$ & Hypothetical protein \\
\hline H9 & $\mathrm{G}-\mathrm{C}$ & $2,388,916$ & Hypothetical protein \\
\hline $\mathrm{H} 5$ & $\mathrm{~T}-\mathrm{C}$ & $2,389,387$ & Hypothetical protein \\
\hline $\mathrm{H} 19$ & G-A & $1,062,031$ & Hypothetical protein \\
\hline $\mathrm{H} 26$ & G-T & $1,106,182$ & Hypothetical protein \\
\hline $\mathrm{H} 27$ & G-T & $1,683,477$ & Hypothetical protein \\
\hline $\mathrm{H} 15$ & $A-T$ & $2,363,489$ & Hypothetical protein \\
\hline \multicolumn{4}{|l|}{ B) } \\
\hline $\mathrm{H} 1$ & $\mathrm{~T}-\mathrm{C}$ & $13,003,993$ & DUF3310 domain-containingprotein \\
\hline $\mathrm{H} 2$ & G-T & $1,307,219$ & Phage tail measure protein \\
\hline H6 & T-A & $1,314,894$ & Phage tail tape measure protein \\
\hline $\mathrm{H} 23$ & $\mathrm{~T}-\mathrm{C}$ & $1,300,393$ & VRR-NUC domain-containing protein \\
\hline $\mathrm{H} 11$ & $A-T$ & $2,467,036$ & Phage antirepressor Ant \\
\hline $\mathrm{H} 12$ & $C-G$ & $2,473,719$ & recombinase family protein \\
\hline $\mathrm{H} 15$ & G-A & $1,323,444$ & DUF3800 domain-containing protein \\
\hline $\mathrm{H} 16$ & T-A & 447,408 & Polysaccharide deacetylase \\
\hline $\mathrm{H} 17$ & T-A & 463,360 & Internalin A \\
\hline $\mathrm{H} 18$ & T-A & 465,225 & Internalin \\
\hline $\mathrm{H} 19$ & C-A & $2,932,396$ & 6-phospho-beta-glucosidase \\
\hline $\mathrm{H} 21$ & T-A & $1,146,752$ & dTDP-4-dehydrorhamnose reductase \\
\hline $\mathrm{H} 22$ & $\mathrm{~T}-\mathrm{A}$ & $2,347,583$ & Oligoendopeptidase F \\
\hline
\end{tabular}

Table 2 Composition of the annotated high impact SNVs in the persistent groups A (Table A) and B (Table B) in Listeria monocytogenes strains isolated from an industrial slaughterhouse over four weeks with their position and the altered nucleotide according to the references of the respective persistent groups (Continued)

\begin{tabular}{clll}
\hline SNVs & REF-ALT & Position & Protein inference \\
\hline H26 & G-T & 431,637 & alpha-mannosidase \\
H27 & G-T & 972,616 & GntR family transcriptional regulator \\
H8 & T-G & $2,432,776$ & Competence protein Comk \\
H13 & G-T & $1,307,219$ & Peptidase \\
H5 & G-A & $2,465,545$ & Hypothetical protein \\
H9 & G-T & $2,445,638$ & Hypothetical protein \\
H20 & G-A & $2,940,879$ & Hypothetical protein \\
H24 & A-C & $2,458,383$ & Hypothetical protein \\
H25 & A-G & 79,636 & Hypothetical protein \\
H28 & A-T & $1,430,257$ & Hypothetical protein \\
H29 & A-T & 444,637 & Hypothetical protein \\
H10 & G-T & $2,461,077$ & hypothetical protein \\
H14 & G-T & $2,445,638$ & Hypothetical protein \\
\hline
\end{tabular}

${ }^{\mathrm{a}}$ REF-ALT Reference-Alteration: Definition of the nucleotides present in the reference genome and their substitution after the mutation in the genomes of this study

presence of $b c r A B C$, a resistance gene cassette to $\mathrm{BC}$, a commonly used agri-food sanitizers [17, 20-23]. More importantly, this genetic determinant was present in only persistent group B and in its closely related sporadic strain p959, while the stress response island genes (ssi1) were present in all strains except p957 and p983 (Fig. 4). The $b c r A B C$ cassette was identified in a plasmid with $80 \mathrm{kbp}$ in all the persistent strain group B with $100 \%$ similarity with plasmid pLM80-cont 507, previously described [41] with accession number of AADR01000010 (Fig. 5). In addition to $b c r A B C$, this plasmid was identified as a vector for cadmium and arsenic resistance as well [41]. To confirm the presence of the $b c r A B C$ genes in only the group $\mathrm{B}$, a PCR was conducted in all studied isolates. The PCR confirmed the presence of the $b c r A B C$ cassette in the group $B$ and its absence in the group $A$ and in sporadic strains (Table 3). Furthermore, using the CMI test, we observed growth in all isolates from the group $\mathrm{B}$ at $6.25 \mathrm{ppm}$ of $\mathrm{BC}$, indicating decrease of sensitivity to this compound, while the rest of isolates from the group A and $\mathrm{C}$ did not grow at this concentration (Table 3).

\section{$B C$ effect on biofilm ability is strain and concentration dependent}

In order to investigate the ability of biofilm formation by strains from the persistent group A, B and the sporadic strains in the presence and absence of $\mathrm{BC}$, microtiter plate assay for biofilm growth was performed on all isolates. Since only strains from group B grew at $3.125 \mathrm{ppm}$ 


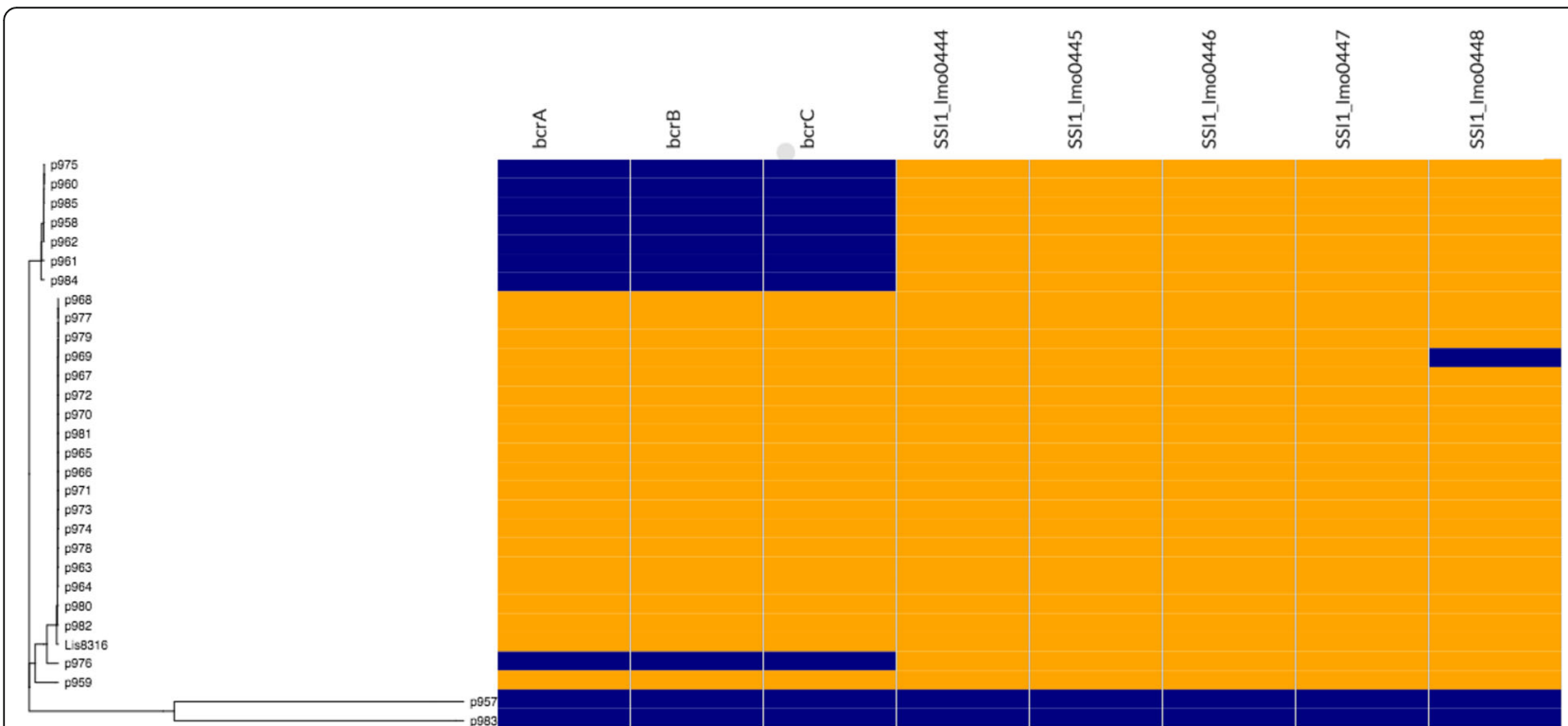

Fig. 4 Phylogenetic distribution of the resistance genes bcrABC and stress response genes (ssi-1) in Listeria monocytogenes strains isolated from an industrial slaughterhouse over four weeks; the presence-absence heatmap of the bcrABC and ssi-1 in the persistent and sporadic groups are shown in orange when present and blue when absent

and strains from groups $\mathrm{A}$ and $\mathrm{C}$ grew in the presence of $0.78 \mathrm{ppm}$ of $\mathrm{BC}$, comparisons were done at the latter concentration. Results showed no significant difference between isolates from the three groups in absence or presence of BC (Fig. 6a and b, respectively), in fact all the strains were able to form biofilm and seem to have an equal ability for biofilm formation. To study if $\mathrm{BC}$ affected the biofilm formation of strains in each group, biofilms formed in the presence of $\mathrm{BC}$ at $3.125 \mathrm{ppm}$ (for group $\mathrm{B}$ strains) and $0,78 \mathrm{ppm}$ were compared to the biofilms formed in the absence of BC. Results showed that biofilms formed in presence of $\mathrm{BC}$ decreased for all groups at all concentrations of $\mathrm{BC}$, but the differences were not significant for group $\mathrm{A}$ and $\mathrm{C}$ strains grown in the presence of a sublethal concentration of $0.78 \mathrm{ppm}$ compared to the biofilms grown in the absence of $\mathrm{BC}$ (Fig. 6c). In contrast, for group B strains, biofilm formation in the presence of $\mathrm{BC}$ at a sublethal concentration of $3.125 \mathrm{ppm}$ was significantly lower than growth in the absence of BC (Fig. 6c).

\section{Discussion}

The aim of this work was to identify genetic determinants that could be associated with persistence of $L$. monocytogenes strains within the slaughterhouse environment. We were especially interested in the potential role of genetic determinants related to resistance to quaternary ammonium, an antimicrobial compound commonly used as a disinfectant in slaughterhouses.

The persistence phenotype of some $L$. monocytogenes strains has been previously reported $[3,9,13]$, however, the reason why these strains can persist in the food processing environment is yet to be fully understood [7]. Here, we describe genomic characteristics of two unrelated persistent groups of strains isolated from slaughterhouse environments at three different times. Although our sampling interval was relatively short, we believe that the isolation of the same CTs at the same location after daily cleaning and sanitation procedures, is a sufficient parameter to attribute the persistence character to our isolates. Furthermore, a sampling completed 3 years after our sampling for this study at the same location allowed us to isolate the same CT from the group B (Lis8316).

The cgMLST and the SNVphyl analysis confirmed the close genetic relatedness between isolates of pulsotype 1 from group B belonging to ST5 and clonal complex (CC) CC5, a clonal group involved in a variety of food products and processing environments contamination as well as in at least two outbreak listeriosis in the United states [42]. Two different CTs, CT2825 and CT4146 were distinguished in group A strains (pulsotype 16) leading to improved discriminatory power, as reported in previous studies $[26,43]$. These CTs belonged to ST9 which was described previously as highly prevalent in the food associated L. monocytogenes strains [44-46]. The SNVphyl analysis showed the presence of 0 to 13 hqSNV differences in the persistent groups, except for strain p984, in group A, where the number of different hqSNVs reached 25 relatives to the rest of the strains. This result was in accordance with cgMLST typing as this strain had a different CT from the rest of group A. 


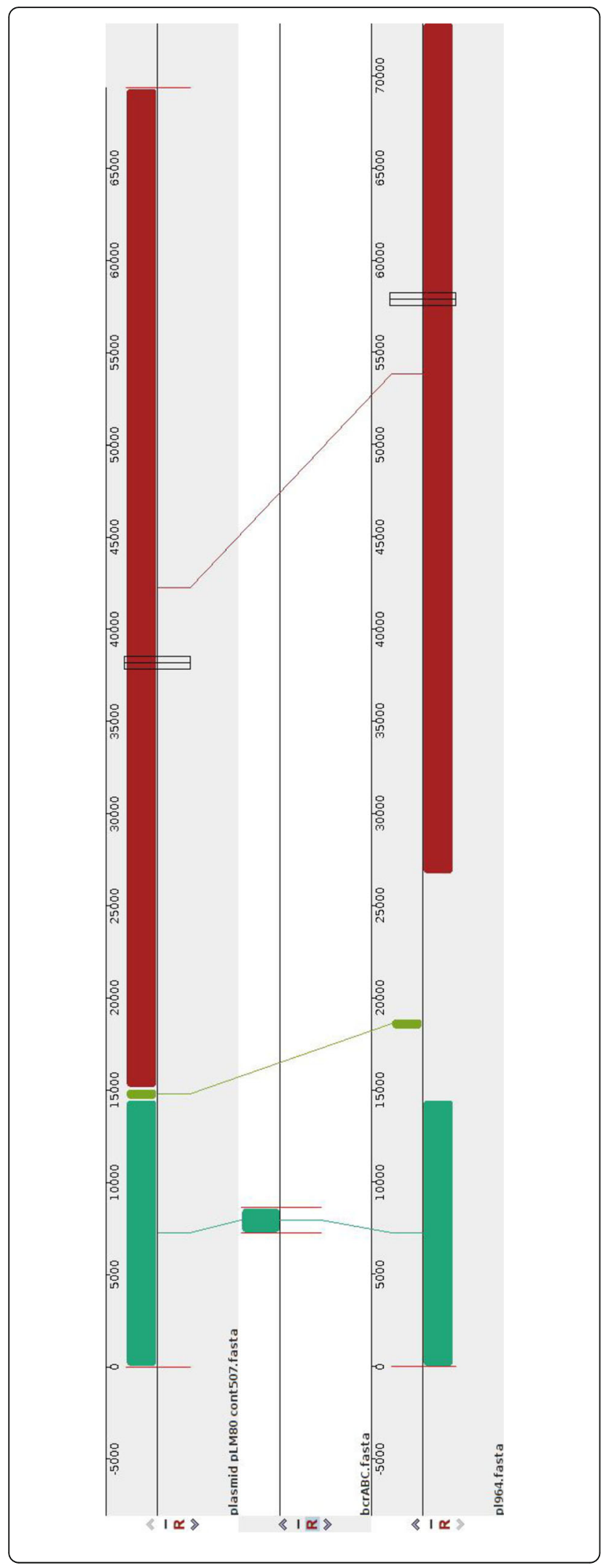

Fig. 5 Multiple sequence alignment of the $b c r A B C$ genes (accession number JX023284.1) and pLM80 cont 507 (accession number: AADR01000010) with a large plasmid identified in in persistent group B as shown in selected strain p964 (p964) and in a closely related strain Lis8316, isolated three years after the isolation of the rest group $B$ strains

The number of hqSNVs did not vary significantly between each period and between strains within the two persistent groups, indicating that the strains were closely related. Indeed, there were no differences between them based on the number of SNVs. Such results are in accordance with other studies that observed limited accumulation of SNVs between two closely related strains isolated from a food processing plant at a 12 year interval [3]. In the current study, a great proportion of SNVs were confined to prophage regions in the genomes and there were very few biologically significant mutations affecting the core genome. Thus, while previous studies showed that prophage insertion into the L. monocytogenes genome was the most important element contributing to the diversification of the strains [47], here we demonstrated in silico that the genes most affected by non-synonymous SNVs were also related to the prophage genes. These findings support the largely recognized view of the high stability of the $L$. monocytogenes genome [26, 37, 47, 48]. The presence of the comk prophage in the group B strains is in accordance with the persistence character of these strains and the association of the ST5 strains to food processing environment as described in previous study [49]. This study allowed the identification of $b c r A B C$ in persistent strains group B. These results complement the Ortiz et al. study [19] where they found the tn6188 transposon, which is

Table $\mathbf{3}$ In silico and phenotypic characteristics of $L$. monocytogenes strains from group $A, B$, and $C$ isolated from an industrial slaughterhouse over a four weeks or three years (for Lis8216) period; In silico identification of determinants for persistence. Phenotypic determination of resistance to $B C$ in $L$. monocytogenes strains isolated: Minimal inhibitory concentrations of all isolates. PCR screening test to identify the bcrABC cassette in the studied strains

\begin{tabular}{llll}
\hline Genetic determinants & \multicolumn{2}{l}{ Strains } & \\
\cline { 2 - 4 } & Group A & Group B & Group C \\
\hline In silico identification & & & \\
bcrABC resistance genes & - & + & - \\
Stress survival islet SSI-1 & + & + & + \\
comk prophages & - & + & - \\
Presence of pLM80 plasmid & - & + & - \\
Phenotypic confirmation & & & \\
bcrABC detection by PCR & - & + & - \\
Minimal inhibitory concentration & - & + & - \\
\hline
\end{tabular}



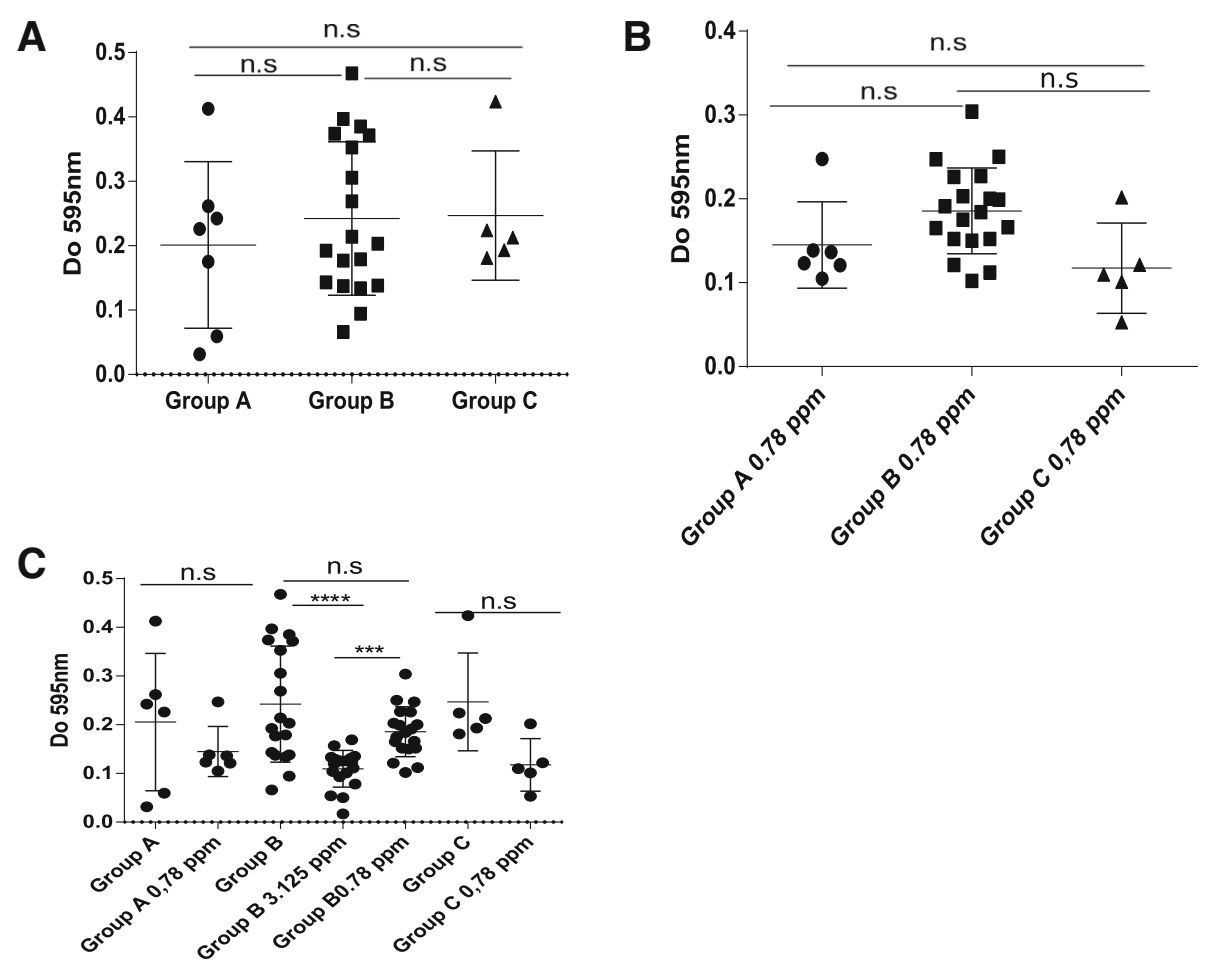

Fig. 6 Biofilm formation ability of L. monocytogenes strains from persistent groups A, B and sporadic group C isolated from a pig slaughterhouse at three or four visits (for group B). a) Comparison of biofilm formation ability between the group A, B and C in the absence of BC. $\mathbf{b}$ ) Comparison of biofilm formation ability between the group A, B and C in the presence of BC. c) Effect of BC at 3.125 and 0.78 ppm on biofilm formation capacity of persistent strains from the group A and B and the sporadic strains C. Significance, n.s: non-significant, ${ }^{* * * *} p<0.0001$, ***: $p=0.0014$.

known to serve as a vector for the $q a c C$ resistance gene transfer in persistent strains. Efflux pump $b c r A B C$ was described in L. monocytogenes for the first time by Elhanafi et al. in a large Listeria monocytogenes plasmid, pLM80 [21]. This plasmid was also previously identified as the vector for cadmium and arsenic resistance determinants in L. monocytogenes [41].

Since then, many studies found the $b c r A B C$ in strains isolated from retail foods $[23,50,51]$. The presence of $b c r A B C$ in strain Lis8216, isolated within a 3-years interval, may indicate the stability of the plasmid harboring this gene in environments where $\mathrm{BC}$ is commonly used. Moreover, persistent group $\mathrm{B}$ was isolated from conveyor surfaces, which have the greatest exposure to BC. However, in our analysis, if these strains were confirmed as less sensitive to $\mathrm{BC}$ treatments, they should still be considered as sensitive to $\mathrm{BC}$ concentrations used in the slaughterhouses where the sampling was done. This apparent paradox was previously reported $[17,25,52]$ and was attributed to a dilution effect during sanitation procedures on wet surfaces, leading to sub-inhibitory concentrations of the disinfectants as reported previously [53]. Persistent group A did not harbor the $b c r A B C$ cassette, and strains from this group were more sensitive to $\mathrm{BC}$ as compared to the ones in group B. Therefore, group A isolates were susceptible to BC. It is noteworthy that these strains were collected from equipment (e.g., saws), places known to be hard to clean, one may suppose that strains residing in such areas could not be exposed frequently to disinfectant. It is therefore easy to hypothesize that strains from group A did not submit pressure selection for $b c r A B C$ acquisition. Results for biofilm formation ability showed no significant differences between strains from persistent and non-persistent groups and all isolates were able to form a $48 \mathrm{~h}$ mature biofilm. Similar results were shown in previous studies where persistent and non-persistent $L$. monocytogenes strains isolated from different sources showed an equal biofilm formation capacity [54]. Same results were obtained from environmental and food product strains in other recent studies where authors suggest that biofilm formation could not be a determinant for persistence [55] or the persistence of studied $L$. monocytogenes strains was not linked to biofilm formation ability and other determinants should be investigated [56]. The presence of $\mathrm{BC}$ at $0.78 \mathrm{ppm}$ during biofilm formation seems not to affect biofilm amount between the three groups, and when strains were 
compared for their ability to form biofilm in the presence and absence of $\mathrm{BC}$, only isolates from group $\mathrm{B}$ seemed to be affected by the sublethal concentration of $\mathrm{BC}$ at $3.125 \mathrm{ppm}$, which may indicate the strain-specific variable responsiveness to the effect of $\mathrm{BC}$ on biofilm formation, and it appears that BC-resistant strains produced significantly less biofilm than susceptible strains as reported previously [24]. It is not understood why BC-resistant L. monocytogenes strains had less ability to form biofilm in the presence of $\mathrm{BC}$, though previous investigators suggested that modification of cellular morphology, phospholipids and fatty acids could be involved in biofilm formation [24].

Further studies using a greater number of unrelated persistent and non persistent strains should be conducted in different conditions, particularly those which mimic the slaughterhouse environment.

Our findings support the hypothesis that persistence, in the case of the strains from the group A, was related to biofilm formation and/or ecological niches formation in hard-to-clean places. Indeed, some authors suggested that persistence could be related to colonization of ecological niches less accessible during sanitation procedures as reported in previous reviews by Carpentier and Cerf (2011) and Ferreira et al. (2014) where authors concluded that there was no association between persistence and any phenotypic characteristics like biofilm formation and resistance to QAC $[7,13]$. While we cannot exclude that some environmental sites were less efficiently cleaned, our findings support that there is not always only one determinant explaining the persistence of $L$. monocytogenes strains and that this phenomenon could be due to multiple factors facilitating the survival of this bacterium. This could explain why some studies focusing on only one determinant, like resistance to QAC, could not find a causal effect with persistence $[9,19]$. We propose that the localized environmental conditions in which strains were isolated in the food processing plant could give clues to identify which determinant(s) enhances the strain's survival. Thus, isolates collected from a conveyor known to be the most exposed surfaces to QAC disinfectants may benefit from QAC resistance while isolates recovered from difficult to clean surfaces may benefit from better biofilm formation phenotypes. We believe that persistent strains possess at least one, but most likely many persistence-associated determinants leading to survival in their specific environment conditions.

\section{Conclusion}

In this study, we described the distribution of non-synonymous SNVs in persistent L. monocytogenes genomes from a food processing environment and found evidence that the presence of genetic determinants associated with resistance to $\mathrm{BC}$ could be linked to the persistence of $L$. monocytogenes strains. The ability to differentiate between sporadic and persistent environmental contamination events using the methods described will be a key element in guiding risk management actions, such as determining the type of sanitary interventions (e.g., aggressive versus standard) required to mitigate identified hazards and adapt cleaning and sanitation procedures to avoid recurrent food contamination.

\section{Additional files}

Additional file 1: Figure S1. Pulsed field gel electrophoresis profile of Ascl and Apa1 restriction enzymes in L. 20 monocytogenes strains isolated from a slaughterhouse over a four weeks period. (PDF 144 kb)

Additional file 2: Table S1. complete annotation of the high impact SNV and function prediction for the group A (spreedsheet group A) and group B (spreed sheet group B). (XLSX 14 kb)

Additional file 3: Table S2. PRJNA433177 Assembly Details and Institut Pasteur IDof the 29 Listeria monocytogenes strains isolated from an industrial slaughterhouse over a 4 weeks period. (XLSX $11 \mathrm{~kb}$ )

\section{Abbreviations}

BC: Benzalkonium chloride; BHI: Brain heart infusion; CAMP: Christie-AtkinsMunch-Petersen; CDC: Center disease and control center; CLSI: Clinical and laboratory standards institute; CT: cgMLST Type; hqSNV: High quality single nucleotide variant; MICs: Minimal inhibitory concentrations; NCBI: National Center for Biotechnology Information; PFGE: Pulsed field gel electrophoresis; PMSC: Premature stop codon; QAC: Quaternary ammonium compound; SMR: Small multidrug resistance; SNV: Single nucleotide variant; ST: Sequence type; TSBYE: Triptic soy broth yeast extract; UVM: University of Vermont Medium; WGS: Whole genome sequencing

\section{Acknowledgements}

We thank Dr. Alexandra Moura from Institut Pasteur for providing the cgMLST of the L. monocytogenes isolates, Dr. Guy Beauchamp from the University of Montreal for statistical analysis, Paul Manninger from the Canadian Food Inspection Agency for the whole-genome sequences of the isolates and Dr. Austin Markell from the Canadian Food Inspection Agency for critical reading of the manuscript.

\section{Funding}

This work was funded by the Canadian Food Inspection Agency (Food 1020 and 1231) and Natural Sciences and Engineering Research Council of Canada (NSERC) RDCPJ 520873-17. The funding organisms did not have any influence neither in the design of the study, in the analysis and the interpretation of data, nor in the writing of the manuscript.

\section{Availability of data and materials}

All data generated or analyzed during this study are included in this published article [and its supplementary information files].

All genomes (except for the strain Lis8316 for which the genome is not published yet as it belongs to another current project) were submitted and published in the GenBank database on the NCBI web site (https://www.ncbi. $\mathrm{nlm}$.nih.gov/assembly) and in the Institut Pasteur database (https:// bigsdb.pasteur.fr/listeria/listeria.html) with the accession number of the bioproject PRJNA433177 and detailed in the Additional file 3: Table S2.

\section{Authors' contributions}

TC, PF, CC, DL and BB designed the study, TC, GLG and CC performed the experiments, TC, CC, IM analyzed the data, TC, BB, PF and SQ interpreted the results. All authors read and approved the final manuscript.

Ethics approval and consent to participate

Not applicable. 


\section{Consent for publication}

Not applicable.

\section{Competing interests}

The authors declare that they have no competing interests.

\section{Publisher's Note}

Springer Nature remains neutral with regard to jurisdictional claims in published maps and institutional affiliations.

\section{Author details}

${ }^{1}$ Chaire de Recherche en Salubrité des Viandes, Faculté de Médecine Vétérinaire, Université de Montréal, Saint-Hyacinthe, QC, Canada. ${ }^{2}$ Centre de Recherche sur les Maladies Infectieuses Porcine et Avicole, Faculté de Médecine Vétérinaire, Université de Montréal, Saint-Hyacinthe, QC, Canada. ${ }^{3}$ Groupe de Recherche et D'enseignement En Salubrité Des Aliments, Faculté de Médecine Vétérinaire, Université de Montréal, Saint-Hyacinthe, QC, Canada. ${ }^{4}$ Food Microbiology Research Team, Canadian Food Inspection Agency, Ottawa, ON, Canada.

Received: 20 August 2018 Accepted: 2 December 2018 Published online: 20 December 2018

\section{References}

1. Charlier C, Perrodeau E, Leclercq A, Cazenave B, Pilmis B, Henry B, Lopes A, Maury MM, Moura A, Goffinet F, et al. Clinical features and prognostic factors of listeriosis: the MONALISA national prospective cohort study. Lancet Infect Dis. 2017;17(5):510-9.

2. de Noordhout CM, Devleesschauwer B, Angulo FJ, Verbeke G, Haagsma J, Kirk M, Havelaar A, Speybroeck N. The global burden of listeriosis: a systematic review and meta-analysis. Lancet Infect Dis. 2014;14(11):1073-82.

3. Orsi RH, Borowsky ML, Lauer P, Young SK, Nusbaum C, Galagan JE, Birren BW, Ivy RA, Sun Q, Graves LM. Short-term genome evolution of Listeria monocytogenes in a non-controlled environment. BMC Genomics. 2008; 9(1):539.

4. Ericsson $\mathrm{H}$, Eklow A, Danielsson-Tham ML, Loncarevic S, Mentzing LO, Persson I, Unnerstad H, Tham W. An outbreak of listeriosis suspected to have been caused by rainbow trout. J Clin Microbiol. 1997;35(11):2904-7.

5. Nakari UM, Rantala L, Pihlajasaari A, Toikkanen S, Johansson T, Hellsten C, Raulo SM, Kuusi M, Siitonen A, Rimhanen-Finne R. Investigation of increased listeriosis revealed two fishery production plants with persistent Listeria contamination in Finland in 2010. Epidemiol Infect. 2014;142(11):2261-9.

6. Independent Investigator into the Listeriosis $\mathrm{O}$, Weatherill S. Report of the independent investigator into the 2008 listeriosis outbreak. Canada; 2009.

7. Ferreira V, Wiedmann M, Teixeira P, Stasiewicz MJ. Listeria monocytogenes persistence in food-associated environments: epidemiology, strain characteristics, and implications for public health. J Food Prot. 2014;77(1): 150-70.

8. Orsi RH, Borowsky ML, Lauer P, Young SK, Nusbaum C, Galagan JE, Birren BW, Ivy RA, Sun Q, Graves LM, et al. Short-term genome evolution of Listeria monocytogenes in a non-controlled environment. BMC Genomics. 2008;9: 539 .

9. Stasiewicz MJ, Oliver HF, Wiedmann M, den Bakker HC. Whole-genome sequencing allows for improved identification of persistent Listeria monocytogenes in food-associated environments. Appl Environ Microbiol. 2015;81(17):6024-37.

10. Simmons C, Stasiewicz MJ, Wright E, Warchocki S, Roof S, Kause JR, Bauer N, Ibrahim S, Wiedmann M, Oliver HF. Listeria monocytogenes and Listeria spp. contamination patterns in retail delicatessen establishments in three U.S. states. J Food Prot. 2014;77(11):1929-39.

11. Ortiz S, Lopez V, Villatoro D, Lopez P, Davila JC, Martinez-Suarez JN. A 3-year surveillance of the genetic diversity and persistence of Listeria monocytogenes in an Iberian pig slaughterhouse and processing plant. Foodborne Pathog Dis. 2010;7(10):1177-84.

12. Lariviere-Gauthier G, Letellier A, Kerouanton A, Bekal S, Quessy S, Fournaise S, Fravalo P. Analysis of Listeria monocytogenes strain distribution in a pork slaughter and cutting plant in the province of Quebec. J Food Prot. 2014; 77(12):2121-8.

13. Carpentier B, Cerf O. Review--persistence of Listeria monocytogenes in food industry equipment and premises. Int J Food Microbiol. 2011;145(1):1-8.
14. Nowak J, Cruz CD, Tempelaars M, Abee T, van Vliet AHM, Fletcher GC, Hedderley D, Palmer J, Flint S. Persistent Listeria monocytogenes strains isolated from mussel production facilities form more biofilm but are not linked to specific genetic markers. Int J Food Microbiol. 2017;256:45-53.

15. Wang J, Ray AJ, Hammons SR, Oliver HF. Persistent and transient Listeria monocytogenes strains from retail deli environments vary in their ability to adhere and form biofilms and rarely have inlA premature stop codons. Foodborne Pathog Dis. 2015;12(2):151-8.

16. Lundén J. Persistent Listeria monocytogenes contamination in food processing plants; 2004.

17. Fox EM, Leonard N, Jordan K. Physiological and transcriptional characterization of persistent and nonpersistent Listeria monocytogenes isolates. Appl Environ Microbiol. 2011;77(18):6559-69.

18. Aase B, Sundheim G, Langsrud S, Rorvik LM. Occurrence of and a possible mechanism for resistance to a quaternary ammonium compound in Listeria monocytogenes. Int J Food Microbiol. 2000;62(1-2):57-63.

19. Ortiz S, López-Alonso V, Rodríguez P, Martínez-Suárez JV. The connection between persistent, disinfectant-resistant Listeria monocytogenes strains from two geographically separate Iberian pork processing plants: evidence from comparative genome analysis. Appl Environ Microbiol. 2016;82(1): 308-17.

20. Müller A, Rychli K, Muhterem-Uyar M, Zaiser A, Stessl B, Guinane CM, Cotter PD, Wagner M, Schmitz-Esser S. Tn6188-a novel transposon in Listeria monocytogenes responsible for tolerance to benzalkonium chloride. PLoS One. 2013;8(10):e76835.

21. Elhanafi D, Dutta $V$, Kathariou S. Genetic characterization of plasmidassociated benzalkonium chloride resistance determinants in a Listeria monocytogenes strain from the 1998-1999 outbreak. Appl Environ Microbiol. 2010;76(24):8231-8.

22. Dutta V, Elhanafi D, Kathariou S. Conservation and distribution of the benzalkonium chloride resistance cassette bcrABC in Listeria monocytogenes. Appl Environ Microbiol. 2013;79(19):6067-74.

23. Rosa Ebner R, Stephan R, Althaus D, Brisse S, Maury M, Tasara T. Phenotypic and genotypic characteristics of Listeria monocytogenes strains isolated during 2011-2014 from different food matrices in Switzerland, vol. 57; 2015.

24. Ortiz S, López V, Martínez-Suárez JV. The influence of subminimal inhibitory concentrations of benzalkonium chloride on biofilm formation by Listeria monocytogenes. Int J Food Microbiol. 2014;189:106-12.

25. Xu D, Li Y, Shamim Hasan Zahid M, Yamasaki S, Shi L, Li J-r, Yan H. Benzalkonium chloride and heavy-metal tolerance in Listeria monocytogenes from retail foods. Int J Food Microbiol. 2014;190:24-30.

26. Moura A, Criscuolo A, Pouseele H, Maury MM, Leclercq A, Tarr C, Björkman JT, Dallman T, Reimer A, Enouf V. Whole genome-based population biology and epidemiological surveillance of Listeria monocytogenes. Nat Microbiol. 2016;2:16185.

27. Hingston P, Chen J, Dhillon BK, Laing C, Bertelli C, Gannon V, Tasara T, Allen K, Brinkman FSL, Truelstrup Hansen L, et al. Genotypes associated with Listeria monocytogenes isolates displaying impaired or enhanced tolerances to cold, salt, acid, or desiccation stress. Front Microbiol. 2017;8. https://doi. org/10.3389/fmicb.2017.00369.

28. Graves LM, Swaminathan B. PulseNet standardized protocol for subtyping Listeria monocytogenes by macrorestriction and pulsed-field gel electrophoresis. Int J Food Microbiol. 2001;65.

29. Bankevich A, Nurk S, Antipov D, Gurevich AA, Dvorkin M, Kulikov AS, Lesin VM, Nikolenko SI, Pham S, Prjibelski AD. SPAdes: a new genome assembly algorithm and its applications to single-cell sequencing. J Comput Biol. 2012:19(5):455-77.

30. Gurevich A, Saveliev V, Vyahhi N, Tesler G. QUAST: quality assessment tool for genome assemblies. Bioinformatics. 2013;29(8):1072-5.

31. Petkau A. SNVPhyl: a single nucleotide variant phylogenomics pipeline for microbial genomic epidemiology. Microb Genom. 2017;3(6). https://doi.org/ 10.1099/mgen.0.000116.

32. Zhou Y, Liang Y, Lynch KH, Dennis JJ, Wishart DS. PHAST: A Fast Phage Search Tool. Nucleic Acids Res. 2011;39(suppl_2):W347-52.

33. Arndt D, Grant JR, Marcu A, Sajed T, Pon A, Liang Y, Wishart DS. PHASTER: a better, faster version of the PHAST phage search tool. Nucleic Acids Res. 2016;44(W1):W16-21.

34. Cingolani P, Platts A, Wang LL, Coon M, Nguyen T, Wang L, Land SJ, Lu X, Ruden DM. A program for annotating and predicting the effects of single nucleotide polymorphisms, SnpEff: SNPs in the genome of Drosophila melanogaster strain W1118; iso-2; iso-3. Fly. 2012;6(2):80-92. 
35. Maury MM, Tsai Y-H, Charlier C, Touchon M, Chenal-Francisque V, Leclercq A, Criscuolo A, Gaultier C, Roussel S, Brisabois A, et al. Uncovering Listeria monocytogenes hypervirulence by harnessing its biodiversity. Nat Genet. 2016;48:308.

36. Gahan CGM, Hill C. Listeria monocytogenes: survival and adaptation in the gastrointestinal tract. Front Cell Infect Microbiol. 2014:4.

37. Kuenne C, Billion A, Mraheil MA, Strittmatter A, Daniel R, Goesmann A, Barbuddhe S, Hain T, Chakraborty T. Reassessment of the Listeria monocytogenespan-genome reveals dynamic integration hotspots and mobile genetic elements as major components of the accessory genome. BMC Genomics. 2013;14(1):47.

38. Wattam AR, Davis JJ, Assaf R, Boisvert S, Brettin T, Bun C, Conrad N, Dietrich EM, Disz T, Gabbard JL, et al. Improvements to PATRIC, the all-bacterial bioinformatics database and analysis resource center. Nucleic Acids Res. 2017:45(D1):D535-42.

39. Hadfield J, Croucher NJ, Goater RJ, Abudahab K, Aanensen DM, Harris SR. Phandango: an interactive viewer for bacterial population genomics. Bioinformatics. 2017:btx610.

40. Sidhu MS, Heir E, Leegaard T, Wiger K, Holck A. Frequency of disinfectant resistance genes and genetic linkage with beta-lactamase transposon Tn552 among clinical staphylococci. Antimicrob Agents Chemother. 2002:46(9): 2797-803.

41. Nelson KE, Fouts DE, Mongodin EF, Ravel J, DeBoy RT, Kolonay JF, Rasko DA, Angiuoli SV, Gill SR, Paulsen IT, et al. Whole genome comparisons of serotype $4 \mathrm{~b}$ and $1 / 2 \mathrm{a}$ strains of the food-borne pathogen Listeria monocytogenes reveal new insights into the core genome components of this species. Nucleic Acids Res. 2004;32(8):2386-95.

42. Chen Y, Luo Y, Curry P, Timme R, Melka D, Doyle M, Parish M, Hammack TS, Allard MW, Brown EW. Assessing the genome level diversity of Listeria monocytogenes from contaminated ice cream and environmental samples linked to a listeriosis outbreak in the United States. PLoS One. 2017;12(2): e0171389.

43. Maury MM, Tsai YH, Charlier C, Touchon M, Chenal-Francisque V, Leclercq A, Criscuolo A, Gaultier C, Roussel S, Brisabois A, et al. Uncovering Listeria monocytogenes hypervirulence by harnessing its biodiversity. Nat Genet. 2016;48(3):308-13.

44. Ebner R, Stephan R, Althaus D, Brisse S, Maury M, Tasara T. Phenotypic and genotypic characteristics of Listeria monocytogenes strains isolated during 2011-2014 from different food matrices in Switzerland. Food Control. 2015; 57:321-6.

45. Chenal-Francisque V, Lopez J, Cantinelli T, Caro V, Tran C, Leclercq A, Lecuit M, Brisse S. Worldwide distribution of major clones of Listeria monocytogenes. Emerg Infect Dis. 2011;17(6):1110-2.

46. Martin B, Perich A, Gomez D, Yanguela J, Rodriguez A, Garriga M, Aymerich T. Diversity and distribution of Listeria monocytogenes in meat processing plants. Food Microbiol. 2014;44:119-27.

47. Orsi RH, Borowsky ML, Lauer P, Young SK, Nusbaum C, Galagan JE, Birren BW, Ivy RA, Sun Q, Graves LM, et al. Short-term genome evolution of Listeria monocytogenes in a non-controlled environment. BMC Genomics. 2008; 9(1):539.

48. Holch A, Webb K, Lukjancenko O, Ussery D, Rosenthal BM, Gram L. Genome sequencing identifies two nearly unchanged strains of persistent Listeria monocytogenes isolated at two different fish processing plants sampled 6 years apart. Appl Environ Microbiol. 2013;79(9):2944-51.

49. Verghese B, Lok M, Wen J, Alessandria V, Chen Y, Kathariou S. Knabel S: comK prophage junction fragments as markers for Listeria monocytogenes genotypes unique to individual meat and poultry processing plants and a model for rapid niche-specific adaptation, biofilm formation, and persistence. Appl Environ Microbiol. 2011;77(10):3279-92.

50. Meier AB, Guldimann C, Markkula A, Pöntinen A, Korkeala H, Tasara T. Comparative phenotypic and genotypic analysis of Swiss and Finnish Listeria monocytogenes isolates with respect to benzalkonium chloride resistance. Front Microbiol. 2017;8:397.

51. Xu D, Nie Q, Wang W, Shi L, Yan H. Characterization of a transferable bcrABC and cadAC genes-harboring plasmid in Listeria monocytogenes strain isolated from food products of animal origin. Int J Food Microbiol. 2016;217:117-22

52. Moretro T, Schirmer BCT, Heir E, Fagerlund A, Hjemli P, Langsrud S. Tolerance to quaternary ammonium compound disinfectants may enhance growth of Listeria monocytogenes in the food industry. Int J Food Microbiol. 2017;241:215-24.
53. Martínez-Suárez JV, Ortiz S, López-Alonso V. Potential impact of the resistance to quaternary ammonium disinfectants on the persistence of Listeria monocytogenes in food processing environments. Front Microbiol. 2016;7.

54. Nilsson RE, Ross T, Bowman JP. Variability in biofilm production by Listeria monocytogenes correlated to strain origin and growth conditions. Int J Food Microbiol. 2011;150(1):14-24.

55. Koreňová J, Oravcová K, Véghová A, Karpí Ková R, Kuchta T. Biofilm formation in various conditions is not a key factor of persistence potential of Listeria monocytogenes in food-processing environment. J Food Nutr Res. 2016;55(2).

56. Costa A, Bertolotti L, Brito L, Civera T. Biofilm formation and disinfectant susceptibility of persistent and nonpersistent Listeria monocytogenes isolates from Gorgonzola cheese processing plants. Foodborne Pathog Dis. 2016;13(11):602-9.

57. Letunic I, Bork P. Interactive tree of life (iTOL) v3: an online tool for the display and annotation of phylogenetic and other trees. Nucleic Acids Res. 2016;44(W1):W242-5.

58. Zhou Z, Alikhan N-F, Sergeant MJ, Luhmann N, Vaz C, Francisco AP, Carrico JA, Achtman M. GrapeTree: Visualization of core genomic relationships among 100,000 bacterial pathogens. bioRxiv. 2017.

\section{Ready to submit your research? Choose BMC and benefit from:}

- fast, convenient online submission

- thorough peer review by experienced researchers in your field

- rapid publication on acceptance

- support for research data, including large and complex data types

- gold Open Access which fosters wider collaboration and increased citations

- maximum visibility for your research: over $100 \mathrm{M}$ website views per year

At BMC, research is always in progress.

Learn more biomedcentral.com/submissions 